\title{
Adaptive Markets Hypothesis for Islamic Stock Portfolios: Evidence from Dow Jones Size and Sector-indices
}

\author{
Amélie CHARLES \\ Audencia Business School \\ Olivier DARNÉ \\ LEMNA, University of Nantes \\ Jae H. KIM \\ Department of Economics and Finance, La Trobe University
}




\begin{abstract}
This paper analyzes the degree of return predictability (or weak-form informational efficiency) of Dow Jones Islamic and conventional size and sectorindices using the data from 1996 to 2013. Employing the automatic portmanteau and variance ratio tests for the martingale difference hypothesis of asset returns, we find that all Islamic and conventional portfolio returns have been predictable in a number of periods, consistent with the implications of the adaptive markets hypothesis. Overall, Islamic portfolios exhibit a higher degree of informational efficiency than the conventional ones, especially in the Consumer Goods, Consumer Services, Financials and Technology sectors. We also find that Islamic portfolios tend to be more efficient than the conventional ones during crisis periods.
\end{abstract}

Keywords: Islamic portfolio, Market Efficiency, Martingale difference hypothesis, Return predictability, Wild bootstrap

JEL Classification: G01, G21, G28. 


\section{Introduction}

Islamic finance, as is well known, is based on the application of classical Islamic law in the management of money: this implies prohibition of interest, excessive risk, gambling; exclusion of investments in arms, alcohol, casinos, tobacco, pornography and pork; and a major attention to social welfare. Like any other modern avatars of ethical investments, such as green, faith or socially responsible investments, the Islamic investing aims at generating low volatility returns and value enhancement opportunities by focusing on low-debt, non-financial, social-ethical investment vehicles (De Lorenzo, 2001). There has been a large-scale growth in Islamic finance and banking in Muslim countries and around the world during the last twenty years. This growth is influenced by a range of factors including broad macroeconomic and structural reforms in financial systems; liberalization of capital movements; privatization; global integration of financial markets; and introduction of innovative and new Islamic products (Zaher and Hassan, 2001). Islamic finance has entered a bright new stage of development, emerging after the global financial crisis as a more equitable and efficient alternative to the Western approach. However, as Abdelsalam and El-Komi (2015) point out, the extant empirical research on Islamic finance have been lagging behind; and a great deal of additional evidence is required to further advance the knowledge in this area.

One of the issues under-researched in Islamic finance is the fundamental question of market efficiency (or return predictability). The efficient market hypothesis (EMH) of Samuelson (1965) and Fama (1965) states that asset prices fully and instantaneously reflect all available and relevant information. Under the weak-form efficiency where the information set consists of past prices and returns, future prices and their returns are purely unpredictable based on past price information; and asset prices follow a martingale process and its increments (returns) are characterized by a martingale difference sequence. Note that the returns following a martingale difference sequence (MDS) are simply uncorrelated in mean, but are allowed to show a higher order dependence such as conditional heteroskedasticity. The martingale is more general and less restrictive for asset prices than the random walk where the returns are assumed to be independent ${ }^{1}$. Recent studies for the EMH on financial markets have tested whether

\footnotetext{
${ }^{1}$ See Escanciano and Lobato (2009b) for the details of martingale process or martingale difference.
} 
asset returns follow an MDS (see, for example, Lim and Brooks 2010; Kim et. al, 2011, Charles et al., 2011).

In the literature of financial market efficiency, Lo's $(2004,2005)$ adaptive market hypothesis (AMH) has emerged as a new paradigm. Departing from a dichotomous (all or nothing) view of market efficiency, the AMH provides a new framework of reconciling the EMH with the notion of bounded rationality. An important implication of the $\mathrm{AMH}$ is that departure from market efficiency (or return predictability) may arise from time to time, due to changing market conditions (cycles, bubbles, crashes, crises, ...) and institutional factors. Recent studies have found that changing market conditions, caused by the events such as Asian financial crisis (e.g., Kim and Shamsuddin, 2008; Lim et al., 2013), and the Global Financial Crisis (e.g., Kim et al., 2011; Smith, 2012), can affect the degree of market efficiency. These events have strong implications for the psychology of market participants and the way they incorporate new information to prices, which in turn may generate time variation in the degree of return predictability.

Despite growing interest in Islamic finance, empirical studies that examined the return predictability of Islamic portfolios are not extensive ${ }^{2}$ To the best of our knowledge, only a few studies examine the weak form of the EMH for the Islamic indices (Hassan, 2002; El Khalichi et al., 2014; Rizvi et al., 2014; Jawadi et al., 2015). However, these studies have not not adopted time-varying measures of return predictability to evaluate the martingale difference hypothesis (MDH), except for the study of Sensoy et al. (2015) who implement a time-varying analysis with a rolling sample by applying the permutation entropy approach. We note that the permutation entropy test is designed for the null hypothesis of independent stock returns, which can be too restrictive and unsuitable for stock returns with the MDS properties such as dependence in variance. In addition, the permutation entropy approach does not provide a sensible measure of return predictability. In this paper, improved versions of the autocorrelation test (Ljung and Box, 1978) and variance ratio test (Lo and MacKinlay, 1988) statistics are adopted. That is, we use the wild bootstrap automatic

\footnotetext{
${ }^{2}$ Most of empirical studies investigate the impact of ethical screening on the performance of Islamic indices relative to their conventional counterparts, with mixed evidence on the performance of ethical indices compared to their unscreened counterparts (e.g., Hussein, 2004, 2005; Hussein and Omran, 2005; Girard and Hassan, 2008, 2011; Ho et al., 2014; Jawadi et al., 2014; Sensoy et al., 2015).
} 
variance ratio test of Kim (2009) and the automatic portmanteau test of Escanciano and Lobato (2009a). Notably, these tests are designed to test for the MDS property, being robust to non-normality and conditional heteroscedasticity that are typical features of stock returns (see, for details, Charles et al., 2011). These tests also provide the test statistics that are useful and intuitive measures of the degree of market (in)efficiency or return predictability. Distinctive from past studies, this paper also compares return predictability of Dow Jones Islamic and conventional size and sector-indices. This is based on the salient features of Islamic portfolios distinct from the conventional ones, as discussed in Section 2 of the paper.

The aim of this paper is threefold: (i) evaluate the evolution of return predictability of the Dow Jones Islamic Market (DJIM) index and the Dow Jones Global (DJG) index; (ii) examine whether its evolution is consistent with the $\mathrm{AMH}$; and (iii) compare the return predictability between the DJIM and its conventional counterpart using the portfolios based on size and sectors. This study covers the period 1996-2013, which includes the periods of major financial crises. We also examine how the economic crises, namely Asian Crisis, Dotcom Crisis, Global Financial Crisis and European Sovereign Debt Crisis, affect the degree of return predictability of Islamic and conventional sub-indices. We capture the time-varying return predictability under the $\mathrm{AMH}$, by employing a moving sub-sample window approach.

The main finding of the paper is that all Islamic and conventional returns have been predictable in a number of periods. This means that the Islamic and nonIslamic markets often show departure from market efficiency from time to time, which is consistent with the implications of the AMH. The Islamic sub-indices are found to exhibit more periods of no return predictability than the conventional ones. We find the similar degree of return predictability in Basic Materials, Industrials, Oil \& Gas, Telecommunications, Health Care and Technologies sectors for both Islamic and conventional sub-indices, whereas the Islamic sub-indices are found to be more efficient than the conventional ones for Consumer Goods, Consumer Services, Financials, and Technologies sectors. Finally, we do observe a tendency that Islamic portfolios are more efficient during the crisis periods. The remainder of this paper is organized as follows: Section 2 presents motivation and background of the study including a brief literature review. Section 3 presents the tests for the MDH adopted in this paper; Section 4 provides the data details; and Section 5 reports the empirical 
results. The conclusion is drawn in Section 6.

\section{Motivation and background}

In this section, we provide a discussion as to the features of Islamic stock portfolios, in comparison with the conventional ones, with their implications to the weak-form market efficiency or return predictability. We also provide a brief discussion on the $\mathrm{AMH}$ and literature review of the studies which test for informational efficiency of Islamic portfolios.

\subsection{Market efficiency and Islamic finance}

It is well expected that Islamic and the conventional markets show different features. A range of alternative plausible explanations have been proposed in the literature to explain the difference of risk and performance between the Islamic and conventional indices. First, the relative under-diversification of the Islamic indices due to filtering criteria that remove a large number of Shari'ah non-compliant firms. The systematic exclusion of the largest firms from the broad universe of investable equities included in Islamic indices due to the financial ratios screen implies that the remaining Shari' ah compliant firms are smaller (Hussein and Omran, 2005; Girard and Hassan, 2008; Saiti et al., 2014). Hussein and Omran (2005) and Girard and Hassan (2008) find that Islamic indices are small-cap oriented and conventional indices are relatively more mid-cap focused, whereas Charles et al. (2015) find that both conventional and Islamic indices are rather small-cap oriented. This difference could affect the return predictability of Islamic and Non-Islamic indices, as explained by Lo and Mackinlay (1988). That is, since small-cap firms are traded less frequently than large-cap ones, information would be promptly acted on the prices of large-cap firms and then smallcap firms with a lag. It should thus be expected that the weak-form EMH could be supported for large-cap stock indices, but rejected for small-cap ones. Second, as a result, Shari' ah compliant firms become less diversified and being concentrated in some specific sectors (Hussein and Omran, 2005). Therefore, lower leverage and less diversification are the main distinctive features of Islamic indices. Dewandaru et al. (2015) and Charles et al. (2015) find that DJ Islamic indices are concentrated in Health 
Care, Industrials, Oil \& Gas, and Technology $!^{3}$ The concentration of Islamic and NonIslamic indices in a few sectors can lead difference in return predictability Islamic and conventional sector-indices, and thus suggesting interesting investment opportunities and diversification benefits. Therefore, it is of particular interest to compare the Islamic and conventional size and sector sub-indices in the framework of return predictability. To the best of our knowledge, this study is the first one to analyze and compare return predictability of Dow Jones Islamic and conventional size and sector-indices.

Moreover, recent studies suggest that the ethical and moral rules, together with the high degree of caution of Islamic investments, can make Islamic finance a promising alternative for improved performance, especially in turbulent times with high conventional financial risk. Ho et al. (2014) find that Islamic indices outperformed their conventional counterparts during crisis periods (Dotcom crisis and Global Financial Crisis periods), but the results are inconclusive for the non-crisis periods, by comparing risk-adjusted performance. Jawadi et al. (2014) also show that Islamic indices appear to outperform conventional indices, particularly during the Global Financial Crisis, while non-Islamic indices seem to be preferred in calm periods. Further, Sensoy et al. (2015) show the adverse effects of the Global Financial Crisis on the market efficiency, and find the increased market efficiency in post-crisis period compared to pre-crisis period ${ }^{4}$ Therefore, investigating the issue of the return predictability of Islamic finance compared with conventional finance during crisis periods is especially interesting. It can also have important implications for investors wishing to develop optimal portfolios and to adapt their investment strategies to market phases.

\footnotetext{
${ }^{3}$ Girard and Hassan (2008) find that FTSE Islamic indices are growth oriented and conventional indices are relatively more value focused, and suggest that one reason behind the high proportion of growth stocks may come from the exclusion of value sectors with higher environmental risks, such as Chemical, Energy, and Basic Industries.

${ }^{4}$ Sensoy et al. (2015) study only the Global Financial crisis period and not the other crisis periods, especially the pre-crisis period from December 1998 to November 2007 (including the Dotcom crisis period) and the post-crisis from July 2009 to June 2014 (including the European Sovereign Debt crisis period.
} 


\subsection{Adaptive markets hypothesis}

According to Grossman and Stiglitz (1980), a perfectly efficient market is theoretically impossible because if prices fully reflect all available information, traders would not have any incentive to acquire costly information. In response to this claim, Campbell et al. (1997) propose the notion of relative efficiency, which has led to a shift in research focus from testing the all-or-nothing notion of absolute market efficiency to measuring the degree of market efficiency. There is also a growing empirical literature suggesting that market efficiency varies over time (for a survey, see Lim and Brooks, 2011; Kim et al., 2011).

The AMH of Lo $(2004,2005)$ is developed by coupling the evolutionary principle with the notion of bounded rationality (Simon, 1955) and has emerged as a new paradigm (Verheyden et al., 2015). A bounded rational investor is said to exhibit satisfying rather than optimal behavior. Optimization can be costly and market participants with limited access to information or abilities to process information are merely engaged in attaining a satisfactory outcome. Lo $(2004,2005)$ argues that a satisfactory outcome is attained not analytically, but through an evolutionary process involving trial error and natural selection. The process of natural selection ensures the survival of the fittest and determines the number and composition of market participants. Market participants adapt to constantly changing environment and rely on heuristics to make investment choices. Based on the evolutionary perspective, profit opportunities do exist from time to time. Though they disappear after being exploited by investors, new opportunities are continually being created as groups of market participants, institutions and business conditions change. An important implication of the $\mathrm{AMH}$ is that return predictability can arise time to time due to changing market conditions. Therefore, market efficiency may not follow a secular trend toward greater efficiency as anticipated by proponents of the EMH, but instead can vary in a cyclical

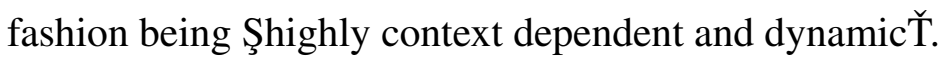

\subsection{Brief literature survey}

There is only a few studies that examined the weak form of the EMH for the Islamic indices. Hassan (2002) examines the issues of market efficiency for the Dow Jones Islamic Market (DJIM) index from January 1996 through December 2000, using 
several statistical tests, such as serial correlation, variance ratio and Dickey-Fuller tests, and finds that DJIM has remarkable market efficiency. He suggests that the absence of professional speculators, liquidity and operational efficiency adversely affects the Islamic markets but it would certainly have a salutary impact on its allocative efficiency. He also shows that thin trading is one of characteristics of the DJIM, which can induce serial correlation in the time series of returns. El Khalichi et al. (2014) explore the weak-form efficiency level of Dow Jones, FTSE, MSCI and S\&P500 Islamic indices by using the Lo-MacKinlay variance ratio tests. Their results show that Islamic indices have the same level of (in)efficiency as conventional ones, and the indices of MSCI and FTSE families are the less inefficient. Rizvi et al. (2014) compare the weak-form efficiency hypothesis between 11 Islamic countries' stock market indices and 11 developed markets' indices by using multifractal de-trended fluctuation analysis. They show that developed countries/regions have a relatively higher efficiency level in comparison to the Islamic countries, indicating the impact of the stage of market development on the efficiency of the market. Jawadi et al. (2015) investigate the weak-form informational efficient hypothesis for three major Dow Jones Islamic stock markets (World, Emerging, and Developed) over the period May 2002 to June 2012. Using rank, Box-Pierce autocorrelation, Lo-MacKinlay variance ratio and BDS tests, they find that emerging Islamic stock markets seem to be less efficient than developed Islamic markets, suggesting interesting investment opportunities and diversification benefits from this region. However, these studies did not use time-varying measures to evaluate the $\mathrm{MDH}$, without link with the AMH, except the study of Sensoy et al. (2015) who implement a time-varying analysis with a rolling sample by applying the permutation entropy approach 5 They find that all indices have different degrees of time-varying predictability and all conventional markets are found to be more efficient compared to their Islamic counter-parts at both country and continent levels from 1998 to 2014. However, in some of the cases, this difference in efficiency is almost indistinguishable. They show that efficiency in these markets depends mostly on liquidity, market quality, institutional characteristics and the country/continent specific investment behavior. They also show that the global financial crisis had an adverse effect on their market efficiency of both indices to

\footnotetext{
${ }^{5}$ Sensoy et al. (2015) also compare their results to those obtained from the Lo-MacKinlay variance ratio test, and find similar results.
} 
varying extents ${ }^{6}$ However, these studies do not examine the predictability of Islamic and non-Islamic indices for size and sectors sub-indices and during crisis periods.

Some studies explore the existence of diversification opportunities using cointegration methodology. Girard and Hassan (2008) and Kok et al. (2009) suggest to use Islamic and conventional indices as asset classes to have more diversification benefits. Kok et al. (2009) exhibit the existence of diversification opportunities by grouping Islamic with conventional and socially responsible indices on the UK market. Majid and Kassim (2010) find that the investors can gain benefits by diversifying in the Islamic stock markets across economic groupings such as that in the developed and developing countries, but limited benefits within the same economic groupings. El Khalichi et al. (2014) show diversification opportunities for Dow Jones and Standard \& Poor's Islamic indices (market-capitalization based Shariah screening requirements), but not for FTSE and MSCI Islamic indices (asset-based Shariah screening requirements). Jawadi et al. (2015) find interesting investment opportunities and diversification benefits from emerging Islamic stock markets than from developed Islamic markets.

\section{Methodology}

We apply the automatic portmanteau test of Escanciano and Lobato (2009a) and automatic variance ratio test of Kim (2009), to evaluate market efficiency or return predictability in this study. The portmanteau test (Ljung and Box, 1978) and variance ratio test (Lo and MacKinlay, 1988) have been widely used in empirical finance as a means of evaluating asset return predictability. However, they are well-known to suffer from deficient properties in small samples, especially under conditional heteroskedasticity widely observed in financial data. In addition, they require ad hoc choices of the lag length or holding periods, further undermining their small sample properties. There have been a number of recent contributions to these tests, which attempt to improve their small sample properties under conditional heteroskedasticity: see, for example, Lobato et al. (2001) for the modified portmanteau test and Kim

\footnotetext{
${ }^{6}$ Others studies examine the efficiency hypothesis of Islamic market indices, for example, Gupta et al. (2014) analyze the predictability of Islamic market indices, using a wide variety of linear and nonlinear predictive regression models, based on a large number of predictors; Alvarez-Diaz et al. (2014) study the forecastability, applying the technique of the nearest neighbor.
} 
(2006) for the wild bootstrap variance ratio tests.

To overcome the problem of choosing the lag length or holding period in an $\mathrm{ad}$ hoc way, Escanciano and Lobato (2009a) propose an automatic portmanteau (AQ) test where selection of lag length is made fully automatic based on a fully datadependent procedure; and Kim (2009) proposes the use of an automatic variance ratio (AVR) test where the optimal holding period is automatically chosen. In their Monte Carlo study, Charles et al. (2011) report that the AVR and AQ tests show highly desirable small sample (size and power) properties, under a wide range of conditionally heteroskedastic asset returns. We note that these two tests are designed to test for the MDS property of asset returns, unlike the permutation entropy test employed by of Sensoy et al. (2015) which tests for the iid (independently and identically distributed) property. It is well-known that a test for iid property may suffer from serious size distortion when the underlying time series follows an MDS (see, for example, Lo and Mackinlay, 1989; and Wright; 2000).

\subsection{Automatic portmanteau test}

Let $Y_{t}$ denote asset return at time $t$, where $t=1, \ldots, T$. Under the null hypothesis of no asset return predictability, $Y_{t}$ is a strictly stationary and ergodic martingale difference sequence (MDS) with appropriate moment conditions (see Escanciano and Lobato, 2009a; Assumption A1). The original portmanteau test statistic is written as

$$
Q_{p}=T \sum_{i=1}^{p} \widehat{\rho}^{2}(i)
$$

where $\hat{\rho}(i)$ is the sample estimator for $\rho(i)$ which is the population autocorrelation of $Y_{t}$ of order $i$. When $Y_{t}$ shows conditional heteroscedasticity, Lobato et al. (2001) propose the use of a robustified test statistic of the form

$$
Q_{p}^{*}=T \sum_{i=1}^{p} \widetilde{\rho}^{2}(i),
$$

where $\widetilde{\rho}(i)=\widehat{\gamma}^{2}(i) / \widehat{\tau}(j), \widehat{\gamma}(i)$ is the sample autocovariance of $Y_{t}$ of order $i$, and $\widehat{\tau}(i)$ is the sample autocovariance of $Y_{t}^{2}$ of order $i$.

The choice of $p$ should be made to implement the test. In order to avoid an ad hoc selection, Escanciano and Lobato (2009a) propose an automatic test where the 
optimal value of $p$ is determined by a fully data-dependent procedure. The test statistic is written as

$$
A Q=Q_{\widetilde{p}}^{*}
$$

where $\widetilde{p}=\min \left\{p: 1 \leq p \leq d ; L_{p} \geq L_{h}, h=1,2, \ldots, d\right\}$ and $d$ is a fixed upper bound, while $L_{p}=Q_{p}^{*}-\pi(p, T)$, where the penalty term $\pi(p, T, q)=p \log (T)$ if $\max _{1 \leq i \leq d} \sqrt{T}|\widetilde{\rho}(i)| \leq \sqrt{2.4 \log (T)}$ and $\pi(p, T, q)=2 p$ if otherwise. Note that the penalty term is a balance between AIC and BIC. Under the null hypothesis of MDS where $\rho(i)=0$ for all $i$, the test statistic asymptotically follows the $\chi_{1}^{2}$ distribution. The null hypothesis of no return predictability is rejected at $\alpha$ level of significance, if the $A Q$ statistics is greater than its asymptomatic critical value $\chi_{1, \alpha}^{2}$, which is the $100(1-\alpha)$ th percentile of the $\chi_{1}^{2}$ distribution.

\subsection{Automatic variance ratio test}

Choi's (1999) AVR test is based on a variance ratio estimator related to the normalized spectral density estimator at zero frequency. Namely,

$$
\widehat{V R}(k)=1+2 \sum_{i=1}^{T-1} k(i / k) \widehat{\rho}(i)
$$

where

$$
k(x)=\frac{25}{12 \pi^{2} x^{2}}\left[\frac{\sin (6 \pi x / 5)}{6 \pi x / 5}-\cos (6 \pi x / 5)\right]
$$

is the quadratic spectral kernel. Note that the estimator given in (4) is a weighted average of sample autocorrelations of $Y_{t}$. According to Choi (1999), under the null hypothesis that $Y_{t}$ is an MDS,

$$
A V R(k)=\sqrt{T / k}[\widehat{V R}(k)-1] / \sqrt{2} \rightarrow_{d} \mathbf{N}(0,1),
$$

as $T \rightarrow \infty, k \rightarrow \infty$, and $T / k \rightarrow \infty$. To implement the test, a choice for the value of lag truncation point $k$ should be made, which is equivalent to the value of holding period in the time domain. Choi (1999) proposes a data-dependent method of choosing $k$ optimally, following Andrews (1991), noting that this choice may exert an enormous impact on the variance ratio test. The $A V R$ test statistic with the optimally chosen lag truncation point is denoted as $A V R\left(k^{*}\right)$. 
To improve the small sample properties of the AVR test under conditional heteroskedasticity, Kim (2009) proposes wild bootstrapping of the test, which is conducted in three stages as follows:

1. Form a bootstrap sample of size $T$ as $Y_{t}^{*}=\eta_{t} Y_{t}(t=1, \ldots, T)$ where $\eta_{t}$ is a random variable with zero mean and unit variance;

2. Calculate $A V R^{*}\left(k^{*}\right)$, the $A V R\left(k^{*}\right)$ statistic calculated from $\left\{Y_{t}^{*}\right\}_{t=1}^{T}$;

3. Repeat 1 and $2 B$ times, to produce the bootstrap distribution of the $A V R$ statistic $\left\{A V R^{*}\left(k^{*} ; j\right)\right\}_{j=1}^{B}$.

The test for $H_{0}$ against the two-tailed alternative is conducted to using the $p$-value, which is estimated as the proportion of the absolute values of $\left\{A V R^{*}\left(k^{*} ; j\right)\right\}_{j=1}^{B}$ greater than the observed statistic $A V R\left(k^{*}\right)$. Alternatively, one may use the $100(1-2 \alpha)$ per cent confidence interval under $H_{0}$, which can be written as $\left[A V R^{*}(\alpha), A V R^{*}(1-\alpha)\right]$, where $A V R^{*}(\alpha)$ denotes the $\alpha^{\text {th }}$ percentile of $\left\{A V R^{*}\left(k^{*} ; j\right)\right\}_{j=1}^{B}$. For $\eta_{t}$, we use the two point distribution proposed by Mammen (1993). The number of bootstrap replications $B$ is set at 500 in this study, which is well-known to be sufficient for $p$-value calculation and the construction of bootstrap confidence interval.

\subsection{Measuring the Degree of Return Predictability}

The $A Q$ and $A V R\left(k^{*}\right)$ tests described above are used to evaluate statistical significance of return predictability, by testing if the population autocorrelation values are 0 . However, evaluation of effect size is also important, which in this case represents the magnitude of the degree of return predictability. Note that the $A Q$ and $A V R\left(k^{*}\right)$ statistics can be used as natural measures of return predictability.7 Since the $A Q$ statistic is the sum of squared sample autocorrelations of $Y_{t}$ to the optimal order (scaled by the sample size), a higher value of $A Q$ statistic indicates a higher degree of return predictability. Similarly, the $A V R\left(k^{*}\right)$ statistic is one plus a weighted sum of the autocorrelations to the optimal order, with positive and declining weights. The main difference between the $A Q$ and $A V R\left(k^{*}\right)$ statistics is that the former treats all sample autocorrelations to the optimal order with equal weights, while the latter provides higher weights to lower order sample autocorrelations.

\footnotetext{
${ }^{7}$ Griffin et al. (2010) use the absolute value of $V R(k)-1$ as a measure of return predictability.
} 


\section{Data Details}

In February 1999, New York-based Dow Jones was the first to launch Shari'ahcompliant indices - i.e. based on a subset of investable equities that are compatible with the Islamic finance principles - in response to the increasing demand for ethical investments from the Muslim community and other socially responsible investors. Broadly speaking, Islamic indices track the performance of a subset of eligible stocks that are already included in the corresponding global indices. To become eligible for inclusion in the Islamic index, a company has to satisfy two main screening criteria (see Dow Jones, 2009):

- The industry screen, which removes the stocks of the companies having primary business activities that are not compatible with the principles of Islamic finance (e.g. alcohol; pork-related products; conventional financial services; entertainment; tobacco; weapons and defense);

- The financial ratios screen, which removes the stocks of the companies based on their levels of leverage or interest income; all of the following financial ratios must not exceed $33 \%$ in order for a stock to be included in the index: (i) the debt ratio; (ii) the ratio of interest income to total revenue; (iii) the ratio of accounts receivables to the market value of total assets.

In addition, the composition of the indices is reviewed on a quarterly basis and the index's weighting scheme follows a free-floating market capitalization, as well as on an ongoing basis to take into account extraordinary events, such as delisting activities, bankruptcies, and mergers. When a new issue is added to the Dow Jones indices, it is also evaluated according to the Dow Jones Islamic (DJI) indices criteria to determine whether it will be included in the DJI indices. All revisions are supervised by an independent Shari' ah board composed of Islamic scholars.

For the purpose of our analysis on any Shariah criteria effect on the predictability, we consider the daily data of the Dow Jones Islamic Market (DJIM) index and the Dow Jones Global (DJG) index, spanning January $1^{\text {st }}$, 1996 to March 15 ${ }^{\text {th }}$, 2013 (3,653 observations). We study (1) the corresponding sub-indices based on size (proxied by the free float-adjusted market capitalization) and classified into three categories: large-, mid- and small-caps; and (2) the corresponding sector-indices 
and classified according to the Industry Classification Benchmark into ten categories: Basic Materials, Consumer Goods, Consumer Services, Financial, Health Care, Industrials, Oil and Gas, Technology, Telecommunications, and Utilities. The daily returns are computed as the natural logarithmic first difference of the daily closing prices, which are obtained from Datastream Thomson. The logarithmic stock returns are multiplied by 100 to avoid convergence problems.

Table 1 presents the descriptive statistics for the log-returns of sector and sizeindices. The Islamic indices display higher mean returns than the conventional market indices but they are also slightly more volatile, as also noted by Charles et al. (2015). All the returns are clearly non-normal, showing evidence of negative excess skewness and excess kurtosis, except for the Technology sector displaying positive skewness. Note that the Financial and Utilities sectors of the DJIM have positive skewness whereas their counterpart of the DJG are negative, suggesting some difference in the behavior of the returns. The Lagrange Multiplier (LM) test for the presence of the $\mathrm{ARCH}$ effect indicates that the returns show strong conditional heteroscedasticity, which is a typical feature of financial returns at the daily frequency. The strong evidence of non-normality and conditional heteroskedasticity suggest that the AQ and AVR tests employed in this paper are well-suited for the data.

In order to examine how return predictability changes depending on the major crises, we define sub-periods according to the periods of (non)crises: (i) Asian Financial Crisis from June 1997 to January 1998; (ii) Dotcom Crisis (from March 2000 to October 2002; (iii) Global Financial Crisis (GFC) from July 2007 to June 2009; and (iv) European Sovereign Debt Crisis from December 2009 to December 2012.

\section{Empirical Results}

In this section, we present and discuss the empirical results. We pay attention to the time-variation of the degree of return predictability for a range of Islamic and conventional portfolios, in association with the ADH. Given the observations made by the past studies that Islamic portfolios outperform the conventional ones during crisis times, we also evaluate the return predictability during different crisis periods in recent years. 


\subsection{Evaluating time-varying return predictability}

To evaluate time-varying return predictability, we use moving sub-sample window of 2 years, which consists of approximately 520 daily observations. This sample size is large enough to ensure desirable size and power properties of the tests employed (see Charles et al., 2011). The 2-year window is also suitable to capture the effects of changing market conditions. The first sub-sample window covers the period from January 1996 to December 1997. Then, the window moves forward by one month to cover the period of February 1996 to January 1998. The process continues to the end of data set. Throughout this process, we calculate the AQ and AVR statistics as measures of time-varying return predictability. In this way, the periods or episodes of high degree of return predictability (with statistical significance) is identified, which in turn are related to the corresponding events and shocks. Note that the use of moving sub-sample window approach is not intended for multiple testing in this paper, but adopted as a means of measuring the degree of return predictability over time. It is also an effective guard against data snooping bias (see Hsu and Kuan, 2006).

Figures 1-5 report the AQ statistics obtained from moving sub-sample windows, monthly from January 1998 to March 2013, for size and sector-indices. Note that the results from the AVR test are not reported for simplicity since we have found similar results. $]^{8}$ The AQ statistics are plotted in black line for the Islamic index and in red line for the non-Islamic index, and the horizonal line indicate the $5 \%$ asymptotic critical value of 3.89. The AQ value greater than the critical value indicates the rejection of the null hypothesis of MDH (no return predictability) at 5\% level of significance, which is statistical evidence against weak-from efficiency. In addition, a higher value of the AQ statistic indicates a higher degree of return predictability, as discussed in the previous section.

Figure 1 reports the AQ statistics for all size indices. We observe extensive periods of return predictability where the MDH is rejected most of times, except for the periods of the Dotcom crisis (around 2004) and the GFC (around 2009). The evidence against no return predictability is stronger for the conventional portfolio than Islamic portfolio; and stronger for small-cap and medium-cap portfolio than large-cap portfolio. For example, the median values of AQ statistic for medium-cap

\footnotetext{
${ }^{8}$ The AVR test results are available upon request.
} 
portfolio are 11.39 and 13.22 respectively for Islamic and conventional indices; while those for large-cap portfolio are 7.88 and 9.64 respectively. This means that higher informational efficiency is associated with Islamic and large-cap portfolio. There is also a strong tendency that the degree of return predictability decreases over time, for both Islamic and conventional indices, implying that the markets have become more efficient since late 1990's. It can also be observed that the difference in the degree of the return predictability between Islamic and conventional indices gets smaller over time, and the degree of return predictability has become virtually identical after 2011.

Figures 2 to 5 report the AQ statistics for sector indices. The returns from the Basic Materials sector exhibit a high degree of return predictability for both Islamic and conventional indices, while the two indices show similar pattern over time. For the Consumer Goods and Consumer Services sectors, the two indices show largely different patterns in return predictability. That is, the conventional index shows much higher AQ statistics than the Islamic index almost always, also showing much more extensive periods of return predictability. Similar observations can be made for the Financials sector, where Islamic index shows a substantially lower degree of return predictability than its non-Islamic counterpart nearly all the time. For the Healthcare sector, the AQ statistic is virtually identical for Islamic and non-Islamic indices, while their returns have been unpredictable for most of times except for early 2000's. For the Industrial sector, the two indices have been showing similar pattern, but both indices show strong return predictability over time. The Oil \& Gas and Telecommunications sectors show the pattern of return predictability similar to that of the Healthcare sector, where both Islamic and non-Islamic indices exhibit similar degree of return predictability. For the Technology sector, the Islamic index is found to be much more efficient than conventional index, while no strong difference in the pattern of return predictability is found for the Utilities sector.

The overall results indicate that all Islamic and conventional returns have been predictable in a number of periods. This means that the Islamic and non-Islamic markets often show departure from market efficiency from time to time, which is consistent with the implications of the AMH. However, overall, the Islamic portfolio is found to be more efficient than the conventional portfolio, especially in the Consumer Goods, Consumer Services, Financials, and Technology Sectors. 


\subsection{Return predictability during crisis periods}

We now examine the degree of return predictability of Islamic and conventional subindices during the crisis periods, namely Asian Crisis, Dotcom Crisis, Global Financial Crisis (GFC) and European Sovereign Debt Crisis. Table 2 displays the AQ and AVR test statistics and their $p$-values for size indices. For all size indices, the null hypothesis of MDH (no return predictability) is rejected at 5\% level of significance for both Islamic and conventional indices during the Asian Financial, Dotcom and European Sovereign Debt crises, which is evidence against weak-from efficiency of both markets during these crisis periods. During the GFC, the null of MDH is rejected for the medium and small-cap indices, for both Islamic and conventional indices. For the large-cap index, there is strong evidence of the weak-form efficiency during the GFC, especially for Islamic indices. However, there is also a strong tendency that both AQ and AVR test statistics are smaller for Islamic portfolios, especially for large-cap portfolio, suggesting that a higher degree of informational efficiency is associated with Islamic portfolios during crisis periods.

The results of AQ and AVR tests for sector indices are given in Tables 3 and 4 . For the Basic Materials sector, Islamic and conventional portfolios show similar degree of return predictability: the null hypothesis of no return predictability is rejected for all crisis periods. For the Consumer Goods sector, Islamic and conventional portfolios again show similar test outcomes: strong return predictability for the Asian and European crises, but otherwise for the Dotcom crisis and GFC. For the Consumer Services sector, Islamic portfolio is found to be more efficient during the European crisis and the GFC, while there is a tendency that a lower predictability is associated with Islamic portfolios during other crisis periods. For the Financials sector, the Islamic portfolio is found to be more efficient only during the Asian crisis. For the Healthcare sector, the AQ and AVR tests deliver similar outcomes for both Islamic and conventional portfolios, except for the Asian crisis where the AVR test show efficiency of Islamic portfolio. For Industrials, Oil \& Gas, Technologies, and Telecommunications sectors, the AQ and AVR tests provide the same inferential outcomes for Islamic and conventional portfolios. It is notable that both portfolios are found to be efficient during the GFC for the Oil \& Gas, Technologies, and Telecommunications sectors. For the Utilities sector, the Islamic portfolio is found 
to be clearly more efficient than the conventional one during the Asian crisis, while the two tests deliver similar outcomes for the other crises.

The overall result suggests that there is a strong tendency that Islamic portfolios have been showing a lower degree of predictability during the crisis times. This observation is consistent with the findings of Ho et al. (2014) and Jawadi et al. (2014) that Islamic portfolios outperform the conventional ones during the crisis times. It is also notable that both Islamic and conventional portfolios show a high degree of informational efficiency during the GFC.

\section{Conclusion}

Financial assets that comply with the Islamic law is growing at a fast rate in the global financial markets, attracting a great deal of attention from both academic researchers and practitioners (see, for example, Abdelsalam and El-Komi; 2015). One of the fundamental questions not sufficiently answered in the extant literature is the degree of informational efficiency or return predictability of Islamic portfolios. In this paper, we analyze the degree of informational efficiency of Islamic portfolio, in association with Lo's $(2004,2005)$ adaptive markets hypothesis (AMH). The key questions include how the degree of return predictability evolves over time and whether Islamic portfolio show a higher degree of informational efficiency than the conventional portfolio. These questions are not fully and properly answered in the previous studies. To this end, we conduct an extensive analysis in this paper, using disaggregated data sets and adopting new econometric methods with desirable small sample properties.

This paper evaluates the return predictability of Dow Jones Islamic and conventional portfolios by testing for the martingale difference hypothesis (MDH), using the daily data from 1996 to 2013 . We pay attention to the size and sector indices to reflect the nature of Islamic portfolios which have a tendency of small-cap and of selective industry concentration. We employ the automatic portmanteau test of Escanciano and Lobato (2009a) and automatic variance ratio test of Kim (2009). These tests are explicitly designed to test for the martingale difference property of asset returns and found to possess desirable size and power properties in small samples under non-normality and conditional heteroskedasticity (see Charles et al., 2011). These tests also provide a sensible measures of the degree of return predictability or informational efficiency. 
We find that both Islamic and conventional portfolios have been showing timevarying return predictability. This means that both Islamic and non-Islamic markets show a departure from market efficiency from time to time, which is consistent with the implications of the AMH. However, we find a strong tendency that the Islamic subindices exhibit more periods of no return predictability than the conventional ones. In addition, while both Islamic and conventional portfolio show a similar degree of market efficiency in Basic Materials, Industrials, Oil \& Gas, Telecommunications and Health Care sectors, the Islamic portfolio are found to exhibit a substantially higher degree of informational efficiency in the Consumer Goods, Consumer Services, Financials and Technologies sectors. Finally, we observe evidence that Islamic portfolios tend to be more efficient than the conventional ones during crisis periods. 


\section{References}

[1] Abdelsalam, O., El-Komi, M., 2015. Islamic Finance: An Introduction. Journal of Economic Behavior and Organization, 103, S1-S3.

[2] Alvarez-Diaz, M., Hammoudeh, S., Gupta, R., 2014. Detecting predictable nonlinear dynamics in Dow Jones Islamic Market and Dow Jones Industrial Average indices using nonparametric regressions. North American Journal of Economics and Finance, 29, 22-35.

[3] Andrews, D.W.K., 1991. Heteroskedasticity and autocorrelation consistent covariance matrix estimation. Econometrica, 58, 817-858.

[4] Campbell, J.Y., Lo, A.W., MacKinlay, A.C., 1997. The Econometrics of Financial Markets. Princeton University Press, Princeton.

[5] Charles, A., Darné, O., Kim, J.H., 2011. Small sample properties of alternative tests for martingale difference hypothesis. Economics Letters, 110, 151-154.

[6] Charles, A., Darné, O., Pop, A., 2015. Risk and ethical investment: Empirical evidence from Dow Jones Islamic indices. Research in International Business and Finance, 35, 33-56.

[7] Choi, I., 1999. Testing the random walk hypothesis for real exchange rates. Journal of Applied Econometrics, 14, 293-308.

[8] De Lorenzo, Y.T., 2001. Shariah supervision of islamic mutual funds. Paper in Proceedings of Fifth Harvard University Forum on Islamic Finance, Harvard University.

[9] Dewandarua, G., Bacha, O.I., Masih, A.M.M., Masih, R., 2015. Risk-return characteristics of Islamic equity indices: Multi-timescales analysis. Journal of Multinational Financial Management, 29, 115-138.

[10] El Khalichi, A., Sarkar, K., Arouri, M., Teulon, F., 2014. Are Islamic equity indices more efficient than their conventional counterparts? Evidence from major global index families. Journal of Applied Business Research, 30, 1137-1150. 
[11] Escanciano, J.C., Lobato, I.N., 2009a. An automatic portmanteau test for serial correlation. Journal of Econometrics, 151, 140-149.

[12] Escanciano, J.C., Lobato, I.N., 2009b. Testing the Martingale Hypothesis, in: Patterson, K., Mills, T.C. (Eds.), Palgrave Hand-book of Econometrics, Palgrave MacMillan, New York, pp. 972-1003.

[13] Fama, E., 1965. The behaviour of stock market prices. Journal of Business, 38, 34-105.

[14] Girard, E., Hassan, K.M., 2008. Is there a Cost to Faith-Based Investing? Evidence from FTSE Indices. Journal of Investing, 17, 112-121.

[15] Griffin, J.M., Kelly, P.J., Nardari, F., 2010. Do market efficiency measures yield correct inferences? A comparison of developed and emerging markets. Review of Financial Studies, 23, 3225-3277.

[16] Grossman, S.J., Stiglitz, J.E., 1980. On the impossibility of informationally efficient markets. The American Economic Review, 70, 393-408.

[17] Gupta, R., Hammoudeh, S., Simo-Kengne, B.D., Sarafrazi, S., 2014. Can the Sharia-based Islamic stock market returns beforecasted using large number of predictors and models? Applied Financial Economics, 24, 1147-1157.

[18] Hassan, K.M., 2002. Risk, return and volatility of faith-based investing: The case of the Dow Jones Islamic index. Proceedings of the Fifth Harvard University Forum on Islamic Finance.

[19] Hassan, K.M., Girard, E., 2011. Faith-based ethical investing: The case of Dow Jones Islamic indices. Workin paper, Networks Financial Institute, Indiana State University.

[20] Ho, C.S.F., Rahman, N.A.A., Yusuf, N.H.M., Zamzamin, Z., 2014. Performance of global Islamic versus conventional share indices: International evidence. Pacific-Basin Finance Journal, 28, 110-121.

[21] Hussein, A.K., 2004. Ethical investment: Empirical evidence from FTSE Islamic index. Islamic Economic Studies, 12, 21-40. 
[22] Hussein, A.K., 2005. Islamic investment: Evidence from Dow Jones and FTSE indices. Working paper, Islamic Business Research Centre, Norway.

[23] Hussein, K., Omran, M., 2005. Ethical investment revisited: Evidence from Dow Jones Islamic indices. Journal of Investing, 14, 105-124.

[24] Jawadi, F., Jawadi, N., Cheffou, A.I., 2015. Are Islamic stock markets efficient? A time-series analysis. Applied Economics, 47, 1686-1697.

[25] Jawadi, F., Jawadi, N., Louhichi, W., 2014. Conventional and Islamic stock price performance: An empirical investigation. International Economics, 137, 73-87.

[26] Kim, J.H., 2006. Wild bootstrapping variance ratio tests. Economics Letters, 92, 38-43.

[27] Kim, J.H., 2009. Automatic variance ratio test under conditional heteroskedasticty. Finance Research Letters, 3, 179-185.

[28] Kim, J.H., Shamsuddin, A., 2008. Are Asian stock markets efficient? Evidence from new multiple variance ratio tests. Journal of Empirical Finance, 15, 518532.

[29] Kim, J.H., Lim, K.P., Shamsuddin, A., 2011. Stock return predictability and the adaptive markets hypothesis: Evidence from century long U.S. Data. Journal of Empirical Finance, 18, 868-879.

[30] Kok, S., Giorgioni, G., Laws, J., 2009. Performance of Shariah-compliant indices in London and NY stock markets and their potential for diversification. International Journal of Monetary Economics and Finance, 2, 398-408.

[31] Lim ,K.P., Brooks, R.D., 2010. The evolution of stock market efficiency over time: A survey of the empirical literature. Journal of Economic Surveys, 24, 140 .

[32] Lim ,K.P., Luo, W., Kim, J.H., 2013. Are US stock index returns predictable? Evidence from automatic autocorrelation-based tests. Applied Economics, 45, 953-962. 
[33] Ljung, G.M., Box, G.E.P., 1978. On a measure of lack of fit in time series models. Biometrika, 65, 297-303.

[34] Lo, A.W., 2004. The adaptive markets hypothesis: Market efficiency from an evolutionary perspective. Journal of Portfolio Management, 30, 15-29.

[35] Lo, A.W., 2005. Reconciling efficient markets with behavioral finance: The adaptive markets hypothesis. Journal of Investment Consulting, 7, 21-44.

[36] Lo, A.W., MacKinlay, A.C., 1988. Stock market prices do not follow random walk: Evidence from a simple specification test. The Review of Financial Studies, 1, 41-66.

[37] Lo, A.W., MacKinlay, A.C., 1989. The size and power of the variance ratio test in finite samples: A Monte Carlo investigation. Journal of Econometrics, 40, 203-238.

[38] Lobato, I.N., Nankervis, J.C., Savin, N.E. 2001. Testing for autocorrelation using a modified Box-Pierce Q test. International Economic Review 42, 187-205.

[39] Majid, M.S.A., Kassim, S.H., 2010. Potential diversification benefits across global Islamic equity markets. Journal of Economic Cooperation and Development, 31, 103-126.

[40] Mammen, E., 1993. Bootstrap and wild bootstrap for high dimensional linear models. The Annals of Statistics, 21, 255-285.

[41] Rizvi, S.A.R., Dewandaru, G., Bacha, O.I., Masih, M., 2014. An analysis of stock market efficiency: Developed vs Islamic stock markets using MF-DFA. Physica A, 407, 86-99.

[42] Saiti, B., Bacha, O.I., Masih, M., 2014. The diversification benefits from Islamic investment during the financial turmoil: The case for the US-based equity investors. Borsa Istanbul Review, 14, 196-211.

[43] Samuelson, P.A., 1965. Proof that properly anticipated prices fluctuate randomly. Industrial Management Review, 6, 41-9. 
[44] Sensoy, A., Aras, G., Hacihasanoglu, E., 2015. Predictability dynamics of Islamic and conventional equity markets. The North American Journal of Economics and Finance, 31, 222-248.

[45] Simon, H., 1955. A behavioral model of rational choice. The Quarterly Journal of Economics, 69, 99-118.

[46] Smith, G., 2012. The changing and relative efficiency of European emerging stock markets. The European Journal of Finance, 18, 689-708.

[47] Verheyden, T., De Moor, L., Van den Bossche, F., 2015. Towards a new framework on efficient markets. Research in International Business and Finance, 34, 294 Ü308.

[48] Wright, J.H., 2000, Alternative Variance-Ratio Tests Using Ranks and Signs, Journal of Business \& Economic Statistics, 18, 1-9.

[49] Zaher, T.S., Hassan, M.K., 2001. A comparative literature survey of Islamic finance and banking. Financial Markets, Institutions \& Instruments, 10, 155-199. 
Table 1: Summary statistics

\begin{tabular}{|c|c|c|c|c|c|c|c|}
\hline & Index & Mean & $\begin{array}{l}\text { St. dev. } \\
(\%)\end{array}$ & $\begin{array}{c}\text { Skewness } \\
(\%)\end{array}$ & Kurtosis & JB & $\mathrm{ARCH}$ \\
\hline \multicolumn{8}{|l|}{ Size indices } \\
\hline \multirow[t]{2}{*}{ Large caps } & DJIM & 0.021 & 1.058 & $-0.301^{*}$ & $10.02^{*}$ & $2761.9^{*}$ & $1292.4^{*}$ \\
\hline & DJG & 0.016 & 1.031 & $-0.321^{*}$ & $9.83^{*}$ & $2642.1^{*}$ & $1321.0^{*}$ \\
\hline \multirow[t]{2}{*}{ Medium caps } & DJIM & 0.033 & 1.171 & $-0.408^{*}$ & $7.81^{*}$ & $1518.7^{*}$ & $1238.8^{*}$ \\
\hline & DJG & 0.025 & 1.007 & $-0.525^{*}$ & $9.68^{*}$ & $2279.2^{*}$ & $1386.3^{*}$ \\
\hline \multirow[t]{2}{*}{ Small caps } & DJIM & 0.040 & 1.231 & $-0.404^{*}$ & $6.68^{*}$ & $1010.5^{*}$ & $1256.2^{*}$ \\
\hline & DJG & 0.025 & 1.051 & $-0.546^{*}$ & $8.54^{*}$ & $1688.0^{*}$ & $1217.2^{*}$ \\
\hline \multicolumn{8}{|l|}{ Sector indices } \\
\hline \multirow[t]{2}{*}{ Basic Materials } & DJIM & 0.026 & 1.370 & $-0.501^{*}$ & $11.22^{*}$ & $3088.2^{*}$ & $1500.9^{*}$ \\
\hline & DJG & 0.018 & 1.299 & $-0.519^{*}$ & $11.64^{*}$ & $3278.7^{*}$ & $1564.2^{*}$ \\
\hline \multirow[t]{2}{*}{ Consumer Goods } & DJIM & 0.022 & 0.854 & $-0.225^{*}$ & $9.78^{*}$ & $2677.5^{*}$ & $1026.9^{*}$ \\
\hline & DJG & 0.022 & 0.811 & $-0.156^{*}$ & $10.86^{*}$ & $3308.1^{*}$ & $1055.1^{*}$ \\
\hline \multirow[t]{2}{*}{ Consumer Services } & DJIM & 0.033 & 1.141 & $-0.132^{*}$ & $7.58^{*}$ & $1593.1^{*}$ & $603.1^{*}$ \\
\hline & DJG & 0.021 & 1.009 & $-0.262^{*}$ & $7.71^{*}$ & $1583.9^{*}$ & $913.4^{*}$ \\
\hline \multirow[t]{2}{*}{ Financials } & DJIM & 0.007 & 1.693 & $0.206^{*}$ & $16.39^{*}$ & $6361.7^{*}$ & $942.8^{*}$ \\
\hline & DJG & 0.008 & 1.271 & $-0.177^{*}$ & $12.27^{*}$ & $4071.2^{*}$ & $1109.6^{*}$ \\
\hline \multirow[t]{2}{*}{ Health Care } & DJIM & 0.028 & 0.989 & $-0.215^{*}$ & $8.92^{*}$ & $2229.6^{*}$ & $810.3^{*}$ \\
\hline & DJG & 0.027 & 0.961 & $-0.255^{*}$ & $9.50^{*}$ & $2501.7^{*}$ & $871.5^{*}$ \\
\hline \multirow[t]{2}{*}{ Industrials } & DJIM & 0.022 & 1.145 & $-0.345^{*}$ & $8.39^{*}$ & $1847.4^{*}$ & $1184.7^{*}$ \\
\hline & DJG & 0.016 & 1.082 & $-0.407^{*}$ & $8.45^{*}$ & $1810.6^{*}$ & $1227.0^{*}$ \\
\hline \multirow[t]{2}{*}{ Oil \& Gas } & DJIM & 0.029 & 1.460 & $0.516^{*}$ & $12.07^{*}$ & $3511.8^{*}$ & $1423.4^{*}$ \\
\hline & DJG & 0.029 & 1.417 & $-0.546^{*}$ & $9.78^{*}$ & $3833.4^{*}$ & $1530.1^{*}$ \\
\hline \multirow[t]{2}{*}{ Technology } & DJIM & 0.023 & 1.712 & $0.088^{*}$ & $6.96^{*}$ & $1301.8^{*}$ & $694.6^{*}$ \\
\hline & DJG & 0.022 & 1.616 & 0.045 & $6.96^{*}$ & $1311.2^{*}$ & $720.0^{*}$ \\
\hline \multirow[t]{2}{*}{ Telecommunications } & DJIM & 0.019 & 1.179 & $-0.083^{*}$ & $7.62^{*}$ & $1627.9^{*}$ & $847.0^{*}$ \\
\hline & DJG & 0.011 & 1.134 & $-0.114^{*}$ & $7.78^{*}$ & $1696.5^{*}$ & $990.9^{*}$ \\
\hline \multirow[t]{2}{*}{ Utilities } & DJIM & 0.013 & 1.108 & 0.063 & $20.10^{*}$ & $8537.7^{*}$ & $1334.4^{*}$ \\
\hline & DJG & 0.010 & 0.855 & $-0.176^{*}$ & $18.51^{*}$ & $7585.6^{*}$ & $1591.7^{*}$ \\
\hline
\end{tabular}

Note: ${ }^{*}$ indicates statistical significance at the $5 \%$ level. JB and ARCH are the Jarque-Bera test for non-normality and the LM test for no ARCH effect of order 10, respectively. 
Table 2: AQ and AVR statistics for size indices.

\begin{tabular}{|c|c|c|c|c|}
\hline & \multicolumn{2}{|r|}{ AQ } & \multicolumn{2}{|c|}{ AVR } \\
\hline & Islamic & Non-Islamic & Islamic & Non-Islamic \\
\hline \multicolumn{5}{|l|}{ Large caps } \\
\hline Asian crisis & $\begin{array}{c}12.93^{*} \\
(0.00)\end{array}$ & $\begin{array}{c}21.06^{*} \\
(0.00)\end{array}$ & $\begin{array}{l}2.40^{*} \\
(0.01)\end{array}$ & $\begin{array}{c}2.63^{*} \\
(0.00)\end{array}$ \\
\hline Dotcom crisis & $\begin{array}{c}4.62^{*} \\
(0.03)\end{array}$ & $\begin{array}{l}7.74^{*} \\
(0.01)\end{array}$ & $\begin{array}{l}1.66^{*} \\
(0.04)\end{array}$ & $\begin{array}{c}1.57^{*} \\
(0.05)\end{array}$ \\
\hline European sovereign debt crisis & $\begin{array}{c}12.46^{*} \\
(0.00)\end{array}$ & $\begin{array}{c}13.49^{*} \\
(0.00)\end{array}$ & $\begin{array}{c}2.75^{*} \\
(0.00)\end{array}$ & $\begin{array}{c}2.86^{*} \\
(0.00)\end{array}$ \\
\hline GFC & $\begin{array}{l}0.79 \\
(0.37) \\
\end{array}$ & $\begin{array}{c}3.14^{* *} \\
(0.08)\end{array}$ & $\begin{array}{l}0.09 \\
(0.87)\end{array}$ & $\begin{array}{l}0.76 \\
(0.39) \\
\end{array}$ \\
\hline \multicolumn{5}{|l|}{ Medium caps } \\
\hline Asian crisis & $\begin{array}{c}20.79^{*} \\
(0.00)\end{array}$ & $\begin{array}{c}18.42^{*} \\
(0.00)\end{array}$ & $\begin{array}{c}2.97^{*} \\
(0.00)\end{array}$ & $\begin{array}{l}3.52^{*} \\
(0.00)\end{array}$ \\
\hline Dotcom crisis & $\begin{array}{c}8.69^{*} \\
(0.00)\end{array}$ & $\begin{array}{c}8.36^{*} \\
(0.00)\end{array}$ & $\begin{array}{c}1.64^{* *} \\
(0.06)\end{array}$ & $\begin{array}{l}1.26 \\
(0.12)\end{array}$ \\
\hline European sovereign debt crisis & $\begin{array}{c}11.65^{*} \\
(0.00)\end{array}$ & $\begin{array}{c}11.54^{*} \\
(0.00)\end{array}$ & $\begin{array}{l}2.71^{*} \\
(0.01)\end{array}$ & $\begin{array}{c}2.85^{*} \\
(0.00)\end{array}$ \\
\hline GFC & $\begin{array}{l}5.40^{*} \\
(0.02) \\
\end{array}$ & $\begin{array}{l}7.27^{*} \\
(0.01) \\
\end{array}$ & $\begin{array}{c}1.72^{* *} \\
(0.08) \\
\end{array}$ & $\begin{array}{c}2.01^{*} \\
(0.04)\end{array}$ \\
\hline \multicolumn{5}{|l|}{ Small caps } \\
\hline Asian crisis & $\begin{array}{c}25.29^{*} \\
(0.00)\end{array}$ & $\begin{array}{c}20.07^{*} \\
(0.00)\end{array}$ & $\begin{array}{c}4.31^{*} \\
(0.00)\end{array}$ & $\begin{array}{c}4.52^{*} \\
(0.00)\end{array}$ \\
\hline Dotcom crisis & $\begin{array}{l}5.11^{*} \\
(0.02)\end{array}$ & $\begin{array}{c}4.71^{*} \\
(0.03)\end{array}$ & $\begin{array}{c}1.61^{* * *} \\
(0.08)\end{array}$ & $\begin{array}{l}1.55 \\
(0.14)\end{array}$ \\
\hline European sovereign debt crisis & $\begin{array}{c}9.72^{*} \\
(0.00)\end{array}$ & $\begin{array}{c}9.30^{*} \\
(0.00)\end{array}$ & $\begin{array}{c}3.04^{*} \\
(0.00)\end{array}$ & $\begin{array}{c}3.17^{*} \\
(0.00)\end{array}$ \\
\hline GFC & $\begin{array}{c}7.66^{*} \\
(0.01)\end{array}$ & $\begin{array}{l}7.51^{*} \\
(0.01)\end{array}$ & $\begin{array}{c}2.41^{*} \\
(0.01)\end{array}$ & $\begin{array}{c}2.47^{*} \\
(0.01)\end{array}$ \\
\hline
\end{tabular}

Note: The table displays the AQ and AVR statistics with their $p$-values in brackets. ${ }^{*}$ and ${ }^{* *}$ indicate statistical significance at $5 \%$ and $10 \%$ level. 
Table 3: AQ and AVR statistics for sector indices.

\begin{tabular}{|c|c|c|c|c|}
\hline & \multicolumn{2}{|r|}{ AQ } & \multicolumn{2}{|c|}{ AVR } \\
\hline & Islamic & Non-Islamic & Islamic & Non-Islamic \\
\hline \multicolumn{5}{|l|}{ Basic Materials } \\
\hline Asian crisis & $\begin{array}{c}8.43^{*} \\
(0.00)\end{array}$ & $\begin{array}{l}8.04^{*} \\
(0.00)\end{array}$ & $\begin{array}{c}2.10^{* *} \\
(0.06)\end{array}$ & $\begin{array}{l}3.93^{*} \\
(0.02)\end{array}$ \\
\hline Dotcom crisis & $\begin{array}{c}6.07^{*} \\
(0.01)\end{array}$ & $\begin{array}{c}6.47^{*} \\
(0.01)\end{array}$ & $\begin{array}{l}1.82^{*} \\
(0.05)\end{array}$ & $\begin{array}{l}2.20^{*} \\
(0.02)\end{array}$ \\
\hline European sovereign debt crisis & $\begin{array}{c}27.5^{*} \\
(0.00)\end{array}$ & $\begin{array}{c}29.7^{*} \\
(0.00)\end{array}$ & $\begin{array}{c}3.90^{*} \\
(0.00)\end{array}$ & $\begin{array}{c}4.02^{*} \\
(0.00)\end{array}$ \\
\hline GFC & $\begin{array}{c}12.1^{*} \\
(0.01)\end{array}$ & $\begin{array}{l}12.0^{*} \\
(0.00)\end{array}$ & $\begin{array}{c}2.44^{*} \\
(0.03)\end{array}$ & $\begin{array}{l}2.31^{*} \\
(0.03)\end{array}$ \\
\hline \multicolumn{5}{|l|}{ Consumer Goods } \\
\hline Asian crisis & $\begin{array}{l}10.1^{*} \\
(0.00)\end{array}$ & $\begin{array}{l}8.34^{*} \\
(0.00)\end{array}$ & $\begin{array}{l}1.99^{*} \\
(0.01)\end{array}$ & $\begin{array}{c}1.43^{* *} \\
(0.07)\end{array}$ \\
\hline Dotcom crisis & $\begin{array}{l}7.40^{*} \\
(0.01)\end{array}$ & $\begin{array}{l}1.27 \\
(0.26)\end{array}$ & $\begin{array}{l}0.40 \\
(0.70)\end{array}$ & $\begin{array}{l}0.63 \\
(0.53)\end{array}$ \\
\hline European sovereign debt crisis & $\begin{array}{c}9.26^{*} \\
(0.00)\end{array}$ & $\begin{array}{c}22.3^{*} \\
(0.00)\end{array}$ & $\begin{array}{c}2.34^{*} \\
(0.01)\end{array}$ & $\begin{array}{l}2.54^{*} \\
(0.00)\end{array}$ \\
\hline GFC & $\begin{array}{l}2.48 \\
(0.12)\end{array}$ & $\begin{array}{l}7.10^{*} \\
(0.01)\end{array}$ & $\begin{array}{l}0.50 \\
(0.57)\end{array}$ & $\begin{array}{l}1.12 \\
(0.21)\end{array}$ \\
\hline \multicolumn{5}{|l|}{ Consumer Services } \\
\hline Asian crisis & $\begin{array}{l}15.0^{*} \\
(0.00)\end{array}$ & $\begin{array}{l}19.4^{*} \\
(0.00)\end{array}$ & $\begin{array}{l}2.59^{*} \\
(0.01)\end{array}$ & $\begin{array}{c}2.53^{*} \\
(0.00)\end{array}$ \\
\hline Dotcom crisis & $\begin{array}{c}6.70^{*} \\
(0.01)\end{array}$ & $\begin{array}{c}9.31^{*} \\
(0.00)\end{array}$ & $\begin{array}{l}1.89^{*} \\
(0.02)\end{array}$ & $\begin{array}{l}2.36^{*} \\
(0.02)\end{array}$ \\
\hline European sovereign debt crisis & $\begin{array}{l}1.08 \\
(0.30)\end{array}$ & $\begin{array}{c}6.50^{*} \\
(0.01)\end{array}$ & $\begin{array}{l}1.37 \\
(0.16)\end{array}$ & $\begin{array}{l}2.40^{*} \\
(0.02)\end{array}$ \\
\hline GFC & $\begin{array}{l}0.12 \\
(0.72) \\
\end{array}$ & $\begin{array}{c}3.00^{* *} \\
(0.08)\end{array}$ & $\begin{array}{l}0.51 \\
(0.52) \\
\end{array}$ & $\begin{array}{l}0.87 \\
(0.31) \\
\end{array}$ \\
\hline \multicolumn{5}{|l|}{ Financials } \\
\hline Asian crisis & $\begin{array}{l}0.74 \\
(0.39)\end{array}$ & $\begin{array}{l}54.3^{*} \\
(0.00)\end{array}$ & $\begin{array}{l}1.31 \\
(0.39)\end{array}$ & $\begin{array}{c}3.47^{*} \\
(0.00)\end{array}$ \\
\hline Dotcom crisis & $\begin{array}{l}5.76^{*} \\
(0.02)\end{array}$ & $\begin{array}{c}3.34^{* *} \\
(0.07)\end{array}$ & $\begin{array}{c}2.84^{*} \\
(0.01)\end{array}$ & $\begin{array}{l}0.94 \\
(0.27)\end{array}$ \\
\hline European sovereign debt crisis & $\begin{array}{l}1.67 \\
(0.20)\end{array}$ & $\begin{array}{l}11.0^{*} \\
(0.00)\end{array}$ & $\begin{array}{c}2.07^{* *} \\
(0.06)\end{array}$ & $\begin{array}{c}2.84^{*} \\
(0.00)\end{array}$ \\
\hline GFC & $\begin{array}{l}7.91^{*} \\
(0.00)\end{array}$ & $\begin{array}{l}8.01^{*} \\
(0.00)\end{array}$ & $\begin{array}{c}-3.38^{*} \\
(0.01)\end{array}$ & $\begin{array}{l}2.12^{*} \\
(0.03)\end{array}$ \\
\hline \multicolumn{5}{|l|}{ Health Care } \\
\hline Asian crisis & $\begin{array}{c}4.23^{*} \\
(0.04)\end{array}$ & $\begin{array}{l}6.12^{*} \\
(0.01)\end{array}$ & $\begin{array}{l}1.55 \\
(0.55)\end{array}$ & $\begin{array}{l}1.82^{*} \\
(0.04)\end{array}$ \\
\hline Dotcom crisis & $\begin{array}{l}22.4^{*} \\
(0.00)\end{array}$ & $\begin{array}{l}22.0^{*} \\
(0.00)\end{array}$ & $\begin{array}{c}-0.46 \\
(0.60)\end{array}$ & $\begin{array}{c}-0.30 \\
(0.70)\end{array}$ \\
\hline European sovereign debt crisis & $\begin{array}{l}0.98 \\
(0.32)\end{array}$ & $\begin{array}{l}1.40 \\
(0.24)\end{array}$ & $\begin{array}{l}1.06 \\
(0.22)\end{array}$ & $\begin{array}{l}1.39 \\
(0.16)\end{array}$ \\
\hline GFC & $\begin{array}{l}0.28 \\
(0.60)\end{array}$ & $\begin{array}{l}0.41 \\
(0.52)\end{array}$ & $\begin{array}{l}0.20 \\
(0.81)\end{array}$ & $\begin{array}{l}0.05 \\
(0.91)\end{array}$ \\
\hline
\end{tabular}

Note: The table displays the AQ and AVR statistics with their $p$-values in brackets. ${ }^{*}$ and ${ }^{* *}$ indicate statistical significance at $5 \%$ and $10 \%$ level. 
Table 4: AQ and AVR statistics for sector indices.

\begin{tabular}{|c|c|c|c|c|}
\hline & \multicolumn{2}{|r|}{$\mathrm{AQ}$} & \multicolumn{2}{|c|}{ AVR } \\
\hline & Islamic & Non-Islamic & Islamic & Non-Islamic \\
\hline \multicolumn{5}{|l|}{ Industrials } \\
\hline Asian crisis & $\begin{array}{c}18.2^{*} \\
(0.00)\end{array}$ & $\begin{array}{c}17.9^{*} \\
(0.00)\end{array}$ & $\begin{array}{c}3.82^{*} \\
(0.00)\end{array}$ & $\begin{array}{c}3.32^{*} \\
(0.00)\end{array}$ \\
\hline Dotcom crisis & $\begin{array}{c}10.2^{*} \\
(0.00)\end{array}$ & $\begin{array}{c}12.3^{*} \\
(0.00)\end{array}$ & $\begin{array}{c}2.26^{*} \\
(0.01)\end{array}$ & $\begin{array}{c}2.32^{*} \\
(0.01)\end{array}$ \\
\hline European sovereign debt crisis & $\begin{array}{c}16.2^{*} \\
(0.00)\end{array}$ & $\begin{array}{c}22.2^{*} \\
(0.00)\end{array}$ & $\begin{array}{c}2.97^{*} \\
(0.00)\end{array}$ & $\begin{array}{c}3.35^{*} \\
(0.00)\end{array}$ \\
\hline GFC & $\begin{array}{c}9.08^{*} \\
(0.00)\end{array}$ & $\begin{array}{c}10.7^{*} \\
(0.00)\end{array}$ & $\begin{array}{c}1.88^{* *} \\
(0.05)\end{array}$ & $\begin{array}{c}2.27^{*} \\
(0.03)\end{array}$ \\
\hline \multicolumn{5}{|l|}{ Oil \& Gas } \\
\hline Asian crisis & $\begin{array}{c}54.6^{*} \\
(0.00)\end{array}$ & $\begin{array}{c}51.8^{*} \\
(0.00)\end{array}$ & $\begin{array}{c}2.16^{*} \\
(0.01)\end{array}$ & $\begin{array}{c}2.64^{*} \\
(0.01)\end{array}$ \\
\hline Dotcom crisis & $\begin{array}{c}9.77^{*} \\
(0.00)\end{array}$ & $\begin{array}{c}9.56^{*} \\
(0.00)\end{array}$ & $\begin{array}{c}-0.14 \\
(0.70)\end{array}$ & $\begin{array}{c}-0.16 \\
(0.69)\end{array}$ \\
\hline European sovereign debt crisis & $\begin{array}{c}9.45^{*} \\
(0.00)\end{array}$ & $\begin{array}{l}11.0^{*} \\
(0.00)\end{array}$ & $\begin{array}{c}2.73^{*} \\
(0.00)\end{array}$ & $\begin{array}{c}2.93^{*} \\
(0.00)\end{array}$ \\
\hline GFC & $\begin{array}{l}0.01 \\
(0.94) \\
\end{array}$ & $\begin{array}{l}0.07 \\
(0.80) \\
\end{array}$ & $\begin{array}{l}0.08 \\
(0.84) \\
\end{array}$ & $\begin{array}{l}0.64 \\
(0.52) \\
\end{array}$ \\
\hline \multicolumn{5}{|l|}{ Technologies } \\
\hline Asian crisis & $\begin{array}{c}3.67^{*} \\
(0.05)\end{array}$ & $\begin{array}{c}8.86^{*} \\
(0.00)\end{array}$ & $\begin{array}{l}1.24 \\
(0.14)\end{array}$ & $\begin{array}{c}1.85^{* *} \\
(0.06)\end{array}$ \\
\hline Dotcom crisis & $\begin{array}{l}0.39 \\
(0.53)\end{array}$ & $\begin{array}{l}1.36 \\
(0.24)\end{array}$ & $\begin{array}{l}0.65 \\
(0.40)\end{array}$ & $\begin{array}{l}1.18 \\
(0.19)\end{array}$ \\
\hline European sovereign debt crisis & $\begin{array}{c}5.77^{*} \\
(0.02)\end{array}$ & $\begin{array}{c}7.41^{*} \\
(0.00)\end{array}$ & $\begin{array}{c}2.46^{*} \\
(0.01)\end{array}$ & $\begin{array}{c}2.76^{*} \\
(0.00)\end{array}$ \\
\hline GFC & $\begin{array}{l}0.05 \\
(0.83) \\
\end{array}$ & $\begin{array}{l}0.55 \\
(0.47) \\
\end{array}$ & $\begin{array}{l}0.23 \\
(0.69)\end{array}$ & $\begin{array}{l}0.47 \\
(0.53)\end{array}$ \\
\hline \multicolumn{5}{|l|}{ Telecommunications } \\
\hline Asian crisis & $\begin{array}{c}12.3^{*} \\
(0.00)\end{array}$ & $\begin{array}{c}14.5^{*} \\
(0.00)\end{array}$ & $\begin{array}{c}2.35^{*} \\
(0.00)\end{array}$ & $\begin{array}{c}2.82^{*} \\
(0.00)\end{array}$ \\
\hline Dotcom crisis & $\begin{array}{c}9.13^{*} \\
(0.00)\end{array}$ & $\begin{array}{c}9.07^{*} \\
(0.00)\end{array}$ & $\begin{array}{c}2.69^{*} \\
(0.00)\end{array}$ & $\begin{array}{c}2.79^{*} \\
(0.00)\end{array}$ \\
\hline European sovereign debt crisis & $\begin{array}{c}4.23^{*} \\
(0.04)\end{array}$ & $\begin{array}{c}4.47^{*} \\
(0.03)\end{array}$ & $\begin{array}{c}1.64^{* *} \\
(0.06)\end{array}$ & $\begin{array}{c}2.79^{*} \\
(0.00)\end{array}$ \\
\hline GFC & $\begin{array}{l}0.89 \\
(0.35) \\
\end{array}$ & $\begin{array}{l}0.57 \\
(0.45) \\
\end{array}$ & $\begin{array}{l}0.28 \\
(0.70) \\
\end{array}$ & $\begin{array}{l}0.31 \\
(0.71) \\
\end{array}$ \\
\hline \multicolumn{5}{|l|}{ Utilities } \\
\hline Asian crisis & $\begin{array}{l}0.01 \\
(0.94)\end{array}$ & $\begin{array}{l}8.34^{*} \\
(0.01)\end{array}$ & $\begin{array}{c}-0.03 \\
(0.94)\end{array}$ & $\begin{array}{c}2.06^{*} \\
(0.01)\end{array}$ \\
\hline Dotcom crisis & $\begin{array}{l}0.01 \\
(0.91)\end{array}$ & $\begin{array}{l}0.19 \\
(0.66)\end{array}$ & $\begin{array}{c}-0.14 \\
(0.77)\end{array}$ & $\begin{array}{l}0.39 \\
(0.49)\end{array}$ \\
\hline European sovereign debt crisis & $\begin{array}{c}6.35^{*} \\
(0.01)\end{array}$ & $\begin{array}{c}4.85^{*} \\
(0.03)\end{array}$ & $\begin{array}{c}2.42^{*} \\
(0.01)\end{array}$ & $\begin{array}{l}1.90^{*} \\
(0.03)\end{array}$ \\
\hline GFC & $\begin{array}{l}0.42 \\
(0.52)\end{array}$ & $\begin{array}{l}0.40 \\
(0.53)\end{array}$ & $\begin{array}{l}0.27 \\
(0.75)\end{array}$ & $\begin{array}{c}-0.23 \\
(0.82)\end{array}$ \\
\hline
\end{tabular}

Note: The table displays the AQ and AVR statistics with their $p$-values in brackets. ${ }^{*}$ and ${ }^{* *}$ indicate statistical significance at $5 \%$ and $10 \%$ level. 
Figure 1: AQ statistics for size indexes.

AQ: Large Caps

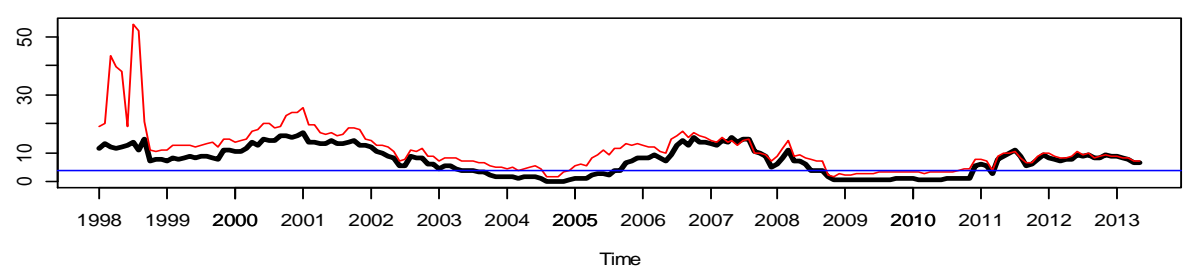

AQ: Medium Caps

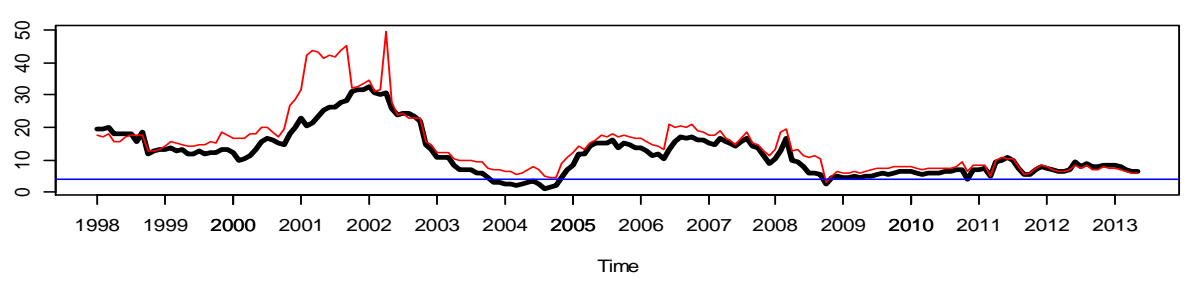

AQ: Small Caps

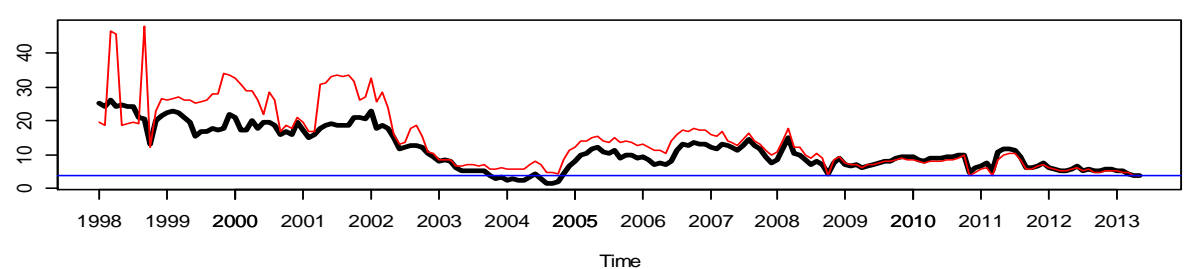

Note: The AQ statistics are plotted in black line for the Islamic index and in red line for the conventional index, and the horizonal line indicate the $5 \%$ asymptotic critical value of 3.89 . 
Figure 2: AQ statistics for sector indexes.

AQ: Basic Materials

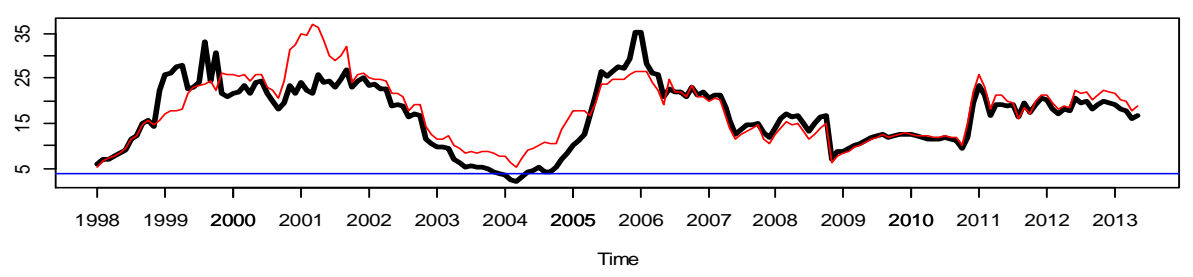

AQ: Consumer Goods

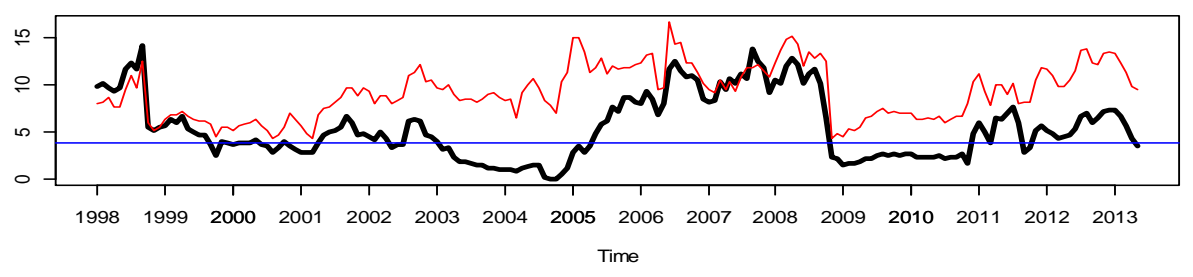

$A Q:$ Consumer Services

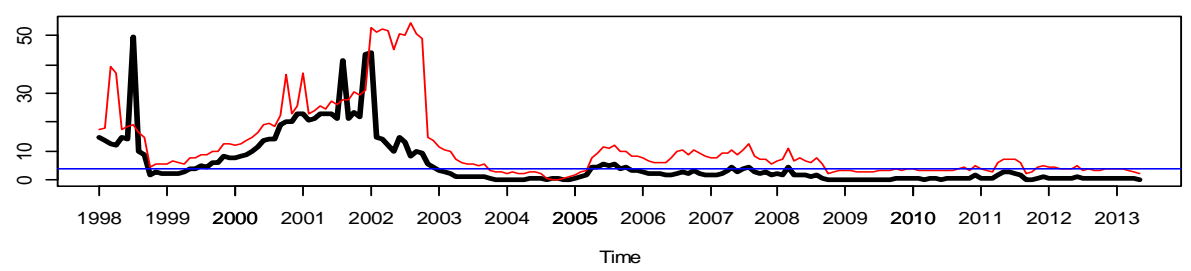

Note: The AQ statistics are plotted in black line for the Islamic index and in red line for the conventional index, and the horizonal line indicate the $5 \%$ asymptotic critical value of 3.89 . 
Figure 3: AQ statistics for sector indexes.

$A Q$ : Financials

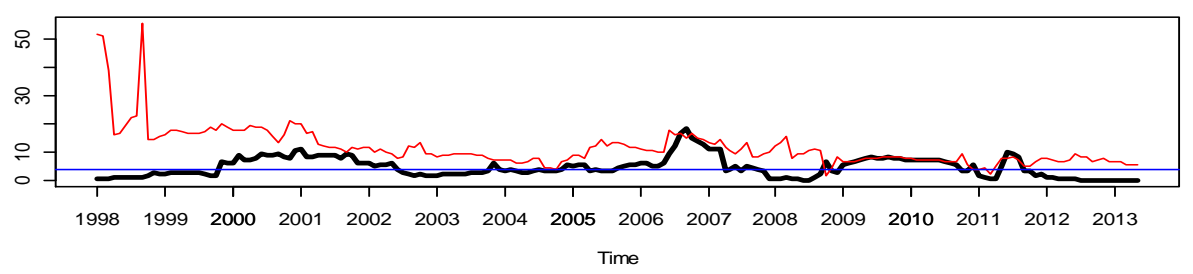

$A Q:$ Healthcare

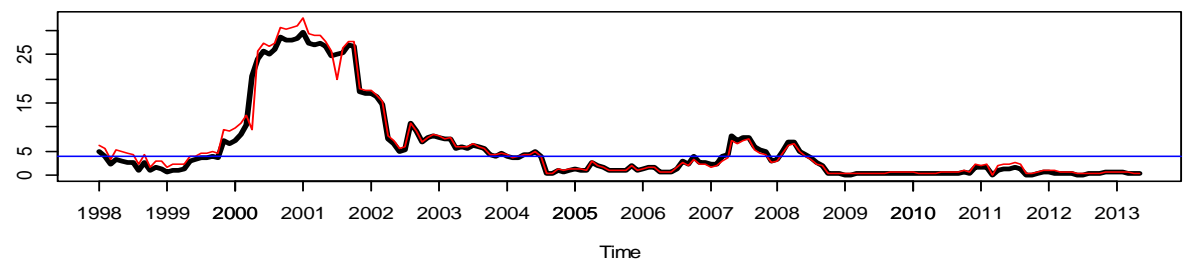

$A Q:$ Industrials

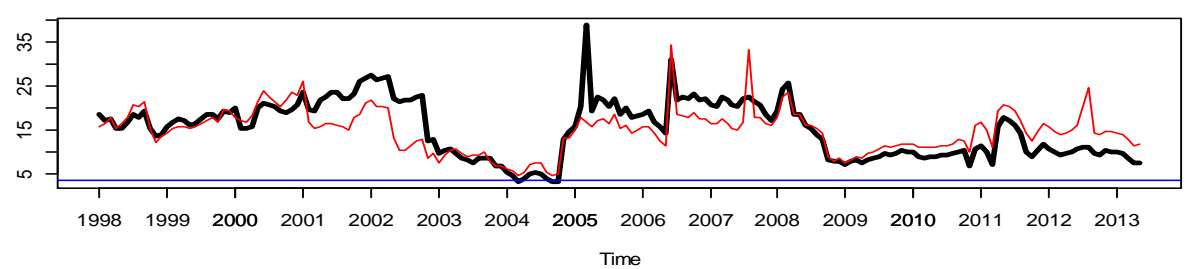

Note: The AQ statistics are plotted in black line for the Islamic index and in red line for the conventional index, and the horizonal line indicate the $5 \%$ asymptotic critical value of 3.89 . 
Figure 4: AQ statistics for sector indexes.

AQ:Oil \& Gas

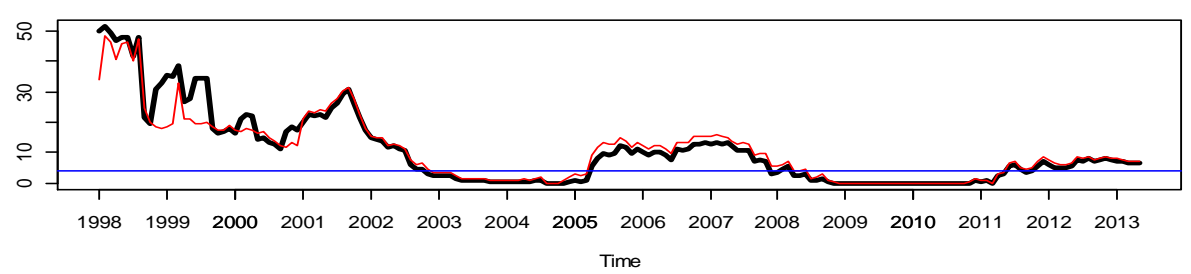

$A Q: T e c h n o l o g y$

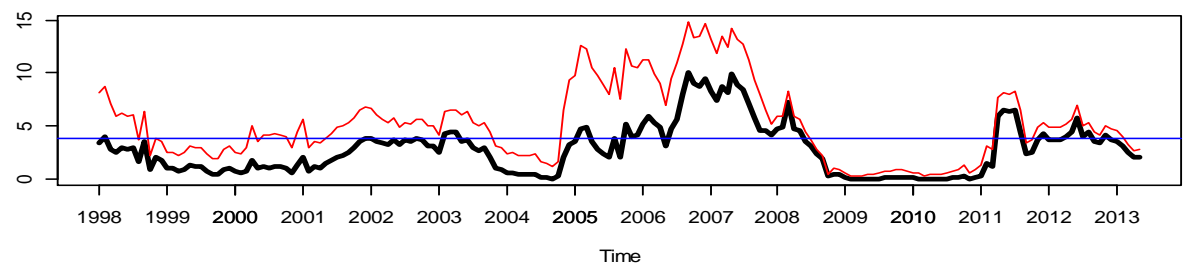

$A Q: T e l e c o m m u n i c a t i o n s$

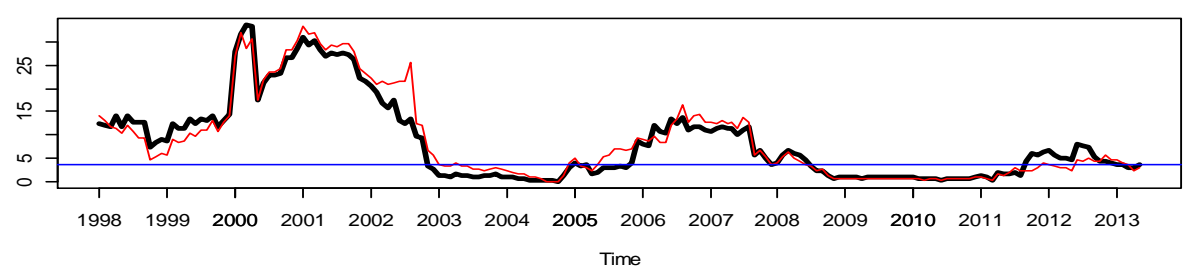

Note: The AQ statistics are plotted in black line for the Islamic index and in red line for the conventional index, and the horizonal line indicate the $5 \%$ asymptotic critical value of 3.89 . 
Figure 5: AQ statistics for sector indexes.

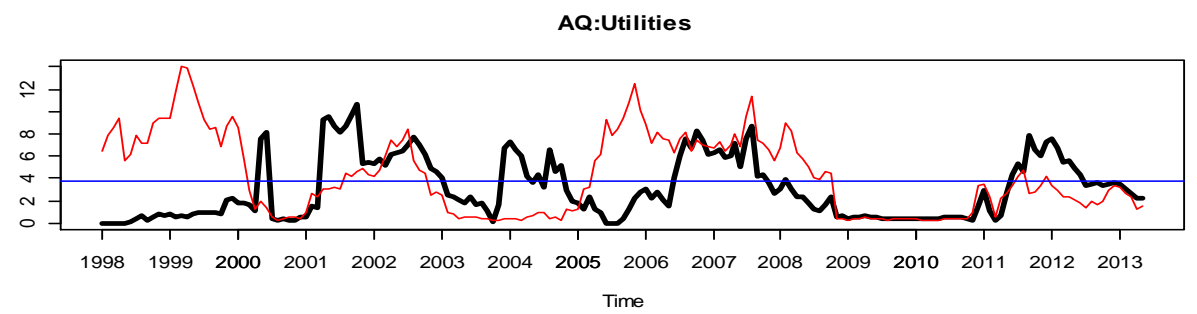

Note: The AQ statistics are plotted in black line for the Islamic index and in red line for the conventional index, and the horizonal line indicate the $5 \%$ asymptotic critical value of 3.89 . 